\section{Entre São Paulo e Paris: o Cálculo vetorial do engenheiro Theodoro Ramos}

\section{Between São Paulo and Paris: the Vector calculus of the engineer Theodoro Ramos}

\author{
Rogério Monteiro Siqueira ${ }^{i}$ \\ Professor, Escola de Artes, Ciências e Humanidades/ \\ Universidade de São Paulo. \\ São Paulo - SP - Brasil \\ orcid.org/0000-0002-5915-0930 \\ rogerms@usp.br
}

Recebido em 13 mar. 2018.

Aprovado em12 out. 2018
SIQUEIRA, Rogério Monteiro. Entre São Paulo e Paris: o Cálculo vetorial do engenheiro Theodoro Ramos. História, Ciências, Saúde - Manguinhos, Rio de Janeiro, v.27, n.1, jan.-mar. 2020, p.151170.

Resumo

Em 1930, o engenheiro Theodoro Ramos publicou pela livraria francesa Albert Blanchard seu livro sobre cálculo vetorial. Este artigo apresenta o contexto de edição da obra, a casa editorial onde foi impressa, o mercado para livros desse tipo na França e o aparecimento desse tema na história do cálculo. Compara conteúdos e aspectos materiais de várias obras similares editadas no período com o livro aqui estudado de maneira a evidenciar tanto suas inovações quanto adesões em relação a esse corpus de livros. Além de seus aspectos intrinsecamente matemáticos, procura capturar as representações, às vezes conflituosas, que a obra recebeu em seu percurso entre São Paulo e a Europa, seja em meio a especialistas ou a seus alunos.

Palavras-chave: cálculo vetorial; Theodoro Ramos (1895-1935); história do livro científico; Librairie Albert Blanchard.

Abstract

In 1930, the engineer Theodoro Ramos published a book on vector calculus through the French publisher Albert Blanchard. The context of is publication, the publishing house where it was printed, the market for books of this kind in France, and the appearance of this topic in the history of calculus are discussed. Some of the contents and material aspects of several works of a similar nature published in the same period are compared with a view to bringing to light the innovations and consistencies of the book in question vis-à-vis this bibliographic corpus. Alongside its intrinsically mathematical aspects, the sometimes conflicting representations of the book by specialists and students in its trajectory between São Paulo and Europe are observed.

Keywords: vector calculus; Theodoro Ramos (1895-1935); history of scientific books; Librairie Albert Blanchard. 
$P^{\prime}$ rimeiro de agosto de 1931. O título em letras maiúsculas e em negrito de uma pequena nota publicada na segunda página do jornal O Estado de S.Paulo chama a atenção do leitor para uma estranha propaganda: "Cálculo vetorial pelo Prof. Theodoro Ramos" (Cálculo vetorial..., 1 ago. 1931). O corpo do texto reproduz em francês parte de uma resenha publicada por René Garnier (10 jan. 1931, p.299), professor da Sorbonne, no jornal de resenhas La Quinzaine Critique:

As lições do Sr. Ramos foram professadas na Escola Politécnica de São Paulo; elas se dirigem aos engenheiros que quiserem se aprofundar na física teórica ... A obra está bem redigida: sua apresentação é excelente. O autor adotou as notações de Grassmann, Burali-Forti e Marcolongo: eu a aprovo sem restrições. ${ }^{1}$

Assim foi que a elite paulistana passou a conhecer a edição e a boa resenha que o livro do professor da Escola Politécnica de São Paulo havia recebido na França, alguns meses antes.

A historiografia tem se detido exaustivamente, por um lado, nas inovações matemáticas que Ramos tentou desenvolver no Brasil e, por outro, na sua atuação como um dos fundadores da Universidade de São Paulo (Bonfim, 2013, 2014; Motoyama, 2006; Silva, 1997, 2006; Studart, Costa, Moreira, 2004). No entanto, ainda não se analisou detidamente como se articulam seus capitais científicos (Bourdieu, 2003), angariados no estudo de objetos matemáticos que demandavam anos de estudo para seu devido controle, e seus capitais políticos, de maneira tal que a elite paulistana confiasse a ele carta branca para contratar professores estrangeiros para as várias áreas da nova Faculdade de Filosofia, Ciências e Letras e também para assumir a sua direção, em 1934.

A explicação não pode prescindir certamente de um estudo de sua vida pregressa como engenheiro atuante nos problemas da cidade de São Paulo e como político ligado às ciências. A vulgarização de seus trabalhos nos jornais da cidade faz parte, portanto, da construção do personagem que transita entre essas duas esferas. A circulação desses trabalhos nessas várias esferas implica evidentemente leituras, adaptações e representações variadas, como foi o caso do livro de cálculo vetorial de Theodoro Ramos.

Em 5 de maio de 1931, três meses antes da propaganda de seu livro, Theodoro Ramos havia se tornado o secretário da Educação e da Saúde Pública do estado de São Paulo durante o governo do interventor militar João Alberto Lins de Barros. ${ }^{2} \mathrm{Na}$ época, a Folha da Manhã o apresentou como membro da "moderna geração paulista" e "jovem cientista", ressaltando sua trajetória junto à Comissão de Águas e Saneamento da capital e como professor da Escola Politécnica de São Paulo. Em um momento de declínio do antigo Partido Republicano Paulista (PRP) e de instabilidade do Partido Democrata (PD) diante do tenentismo (Codato, 2010), Ramos se apresenta em seu discurso de posse como um "profissional paulista, alheio em absoluto às lutas de partidos políticos". Diz ele ainda que não pode deixar de oferecer "a sua colaboração técnica e administrativa à obra de reerguimento do Estado de São Paulo" (Foi nomeado..., 6 maio 1931). Assim, o professor politécnico entra em definitivo para a política como secretário da área de saúde e educação, apresentando as credenciais de um técnico.

Naquele momento, a estratégia textual funcionava por duas razões principais: a recente presença dos engenheiros como prefeitos da cidade de São Paulo era uma delas, sendo José 
Pires do Rio, de 1926 a 1930, o primeiro deles. Em segundo lugar, embora fosse um jovem engenheiro de 36 anos, Ramos havia se saído muito bem na coordenação da Comissão de Saneamento de São Paulo, trabalhando na construção da adutora da Represa Guarapiranga, dando uma solução importante para o problema da água na cidade (Faria, 2009).

Assim, os leitores do jornal conheciam perfeitamente o autor em questão, embora a maioria da população da cidade não tivesse ideia alguma sobre o real conteúdo do livro publicado. Era preciso não só ser engenheiro, mas dominar a teoria do cálculo tensorial, que os currículos das escolas de engenharia não ensinavam na época. Para o público cotidiano do jornal, a abordagem moderna do cálculo que o livro apresentava realmente não interessava. Eles tinham em mãos somente as credenciais do autor da resenha, o professor da Sorbonne René Garnier, e uma citação na mais confortável língua estrangeira para a elite de São Paulo, o francês. Nesse sentido, a nota podia produzir nessa elite um efeito um pouco diferente daquele que veremos na comunidade dos especialistas.

Considerando a presença substantiva do livro científico francês no mercado local, sobretudo para engenheiros (Caramori, 2015; Siqueira, 2017), a recente publicação indicava um feito realmente importante, usado em favor tanto da carreira científica quanto política do jovem engenheiro no governo estadual. Como um jovem membro dos quadros do Partido Democrático, depois Partido Constitucionalista (PC), Theodoro Ramos constrói para si uma identidade pública condizente com a estratégia política em curso, de superação do velho PRP, dos "ilustrados" contra os "carcomidos", ${ }^{3}$ como se costumava dizer na época.

Portanto, da perspectiva de São Paulo, uma história da modernização do cálculo, da homogeneização das notações do cálculo vetorial e, em certo sentido, uma história da matemática moderna não pode deixar de considerar as questões políticas locais, os usos dos estudos no exterior e a posse das mercadorias culturais estrangeiras pela elite local como estratégia de distinção social. Da perspectiva de Paris, a matemática moderna não pode ser explicada sem considerar um mercado vigoroso de impressos científicos que, ao procurar o lucro máximo, publicava um excesso de livros e periódicos para ser vendido fora de Paris. Essa seria uma das possíveis razões para um pequeno editor, como era Albert Blanchard, publicar um livro de cálculo vetorial de um desconhecido na comunidade francesa de matemáticos. Nesse sentido, o internacional não pode ser explicado sem os mercados locais, e vice-versa.

\section{A livraria Albert Blanchard}

A Albert Blanchard Librairie era uma pequena livraria, um negócio familiar, localizado nas vizinhanças da Sorbonne. Não é muito simples saber quais eram todos os membros da família e como estavam distribuídos nas várias posições dos negócios que incluíam a livraria. Infelizmente, seus arquivos desapareceram com a morte do editor, e acabamos por ter que trabalhar majoritariamente com os catálogos impressos nas contracapas, algumas cartas produzidas por integrantes da rede de sociabilidade do editor, bem como algumas fontes secundárias. 
No entanto, verifica-se que as diversas atividades econômicas exercidas pela família foram usadas de maneira complementar: ao mesmo tempo em que Émile Blanchard foi o responsável pela preservação da Casa de Auguste Comte em Paris, na época controlada pela família do brasileiro Paulo Carneiro, ${ }^{4}$ ele também foi responsável pela edição da obra póstuma Wilhelmine, de Clotilde Vaux, na editora da família, a pedido do Apostolado Positivista. Enquanto a edição de Wilhelmine foi totalmente paga pelo apostolado, tendo na capa os positivistas como responsáveis pela edição, as cartas de Auguste Comte e Nísia Brasileira foram oficialmente editadas pela livraria. Assim, não era de todo incomum que a Librairie Albert Blanchard dividisse ou cobrasse os custos da edição de uma obra. Ou seja, os negócios imobiliários e editoriais andavam juntos e se completavam, como já observou Mollier (2010) em seu estudo sobre o mercado editorial francês.

É particularmente interessante observar também que as rivalidades científicas locais de seus autores não interferiam nas lógicas de edição da nova casa editorial. É bem conhecida a oposição que alguns engenheiros tinham em relação aos textos de matemática de Comte na época, tidos por eles como repletos de erros de matemática. Theodoro Ramos era um dos integrantes desse grupo crítico (Siqueira, 2017, 2018; Silva, 1997, 2006). No entanto, ele usa o mesmo caminho previamente explorado pelos positivistas para editar seu livro na França.

Como várias livrarias na região da Sorbonne, a Blanchard costumava editar também teses doutorais dos estudantes da universidade, muito provavelmente pagas por seus autores, como fez com a Wilhelmine de Clotilde Vaux. Tudo leva a crer que essas obras não eram pensadas dentro das coleções da casa editorial porque não aparecem nos vários catálogos que a casa publicou anexos a seus livros e aos quais se tem acesso atualmente.

Analisando a coleção de livros da editora nos catálogos da Biblioteca Nacional da França (https://catalogue.bnf.fr/index.do) e do Sistema Universitário de Documentação (http:// www.sudoc.abes.fr), conclui-se que o livreiro Albert Blanchard publicou suas primeiras obras em 1922, ano em que o editor lançou dois livros originais e uma tabela geológica:

- Introduction au calcul tensoriel et au calcul différentiel absolu. Gustave Juvet. Prefácio de M. Jacques Hadamard. Paris: A. Blanchard. 1922. 107p.

- Temps, espace, matière: leçons sur la théorie de la relativité générale. Hermann Weyl. Tradução da quarta edição alemã por Gustave Juvet e Robert Leroy. Paris: A. Blanchard. 1922. 290p.

- La constitution de la matière. Max Born. Tradução de H. Bellenot. Paris: A. Blanchard. 1922. 88p.

- Les forces de valence et les spectres de Röntgen [Texte imprimé]: deux mémoires sur la structure électronique de l'atome. Walther Kossel. Tradução de M. Golay. Paris: A. Blanchard. 1922. 70p.

- Tableau géologique. Raymond Furon. Paris: A. Blanchard. 1922.

Suas atividades como editor serão interrompidas de 1933 a 1949, por isso consideramos a década de 1922-1932 a primeira fase da casa editorial. Levando em conta os dados globais 
das suas atividades nesse período, a lista de livros editados em 1922 resume as estratégias de negócios de Blanchard nos anos seguintes. Ele intercalará a edição de obras originais com a publicação de teses e de traduções. Dos 94 livros impressos na primeira fase da casa, 20 (21\%) foram teses, 16 (17\%) foram traduções e 58 (62\%) foram originais (Tabela 1).

Tabela 1: Tipos de impressos editados pela Librairie Albert Blanchard de 1922 a 1932

\begin{tabular}{cccccccccccccc}
\hline Ano & 1921 & 1922 & 1923 & 1924 & 1925 & 1926 & 1927 & 1928 & 1929 & 1930 & 1931 & 1932 & Total \\
\hline Originais & 2 & 6 & 3 & 2 & 2 & 12 & 4 & 9 & 6 & 4 & 6 & 2 & 58 \\
Traduções & 0 & 3 & 2 & 0 & 2 & 4 & 1 & 0 & 2 & 2 & 0 & 0 & 16 \\
Teses & 0 & 0 & 0 & 0 & 0 & 4 & 6 & 6 & 2 & 2 & 0 & 0 & 20 \\
\hline
\end{tabular}

Fontes: <https://catalogue.bnf.fr/index.do > e <http://www.sudoc.abes.fr $>$.

Um grupo de tradutores e autores foi aos poucos sendo construído por meio de alianças no mundo científico, numa estratégia similar àquela que a Gauthier-Villars, a grande casa editorial francesa de livros científicos, fez com o matemático Émile Borel. Caroline Ehrhardt (2011) sugere que Borel acabou funcionando como uma espécie de emissário da casa no mundo científico, captando novos autores, tanto franceses como estrangeiros, e participando ativamente na edição da coleção de livros sobre análise matemática, mais tarde conhecida como Coleção Borel.

Assim também Blanchard recorre ao jovem Gustave Juvet (1896-1936) para iniciar seu catálogo. Engenheiro suíço que acabara de chegar a Paris para fazer seu doutorado em matemática na Sorbonne (Alunni, 2009), Juvet publicou seu livro sobre cálculo tensorial e a sua tradução de Tempo, espaço e matéria, de Hermann Weyl, em 1922. Essa tradução, a primeira para o francês do trabalho seminal de Weyl, foi simultânea à tradução para o inglês do mesmo texto. De 1922 até 1929, Blanchard havia publicado dez obras dentro da Coleção de Monografias Científicas Estrangeiras, coordenada por Juvet, que cobria boa parte das traduções da casa. Como se vê, trata-se de um conjunto de traduções de textos sobretudo de física moderna (teoria da relatividade, da radioatividade, quântica, da luz e atômica), escritos por importantes personagens da área da física no período, como Max Born, Arnold Sommerfeld, James Hopwood Jeans, Joseph John Thomson, Levi-Civita e outros (Figura 1).

Assim, ao mesmo tempo que Juvet organiza a coleção de traduções com nomes importantes internacionalmente, ele e outros jovens autores desconhecidos publicam suas primeiras obras na Albert Blanchard.

De fato, analisando o conjunto dos textos editados na primeira fase da editora, são contrastantes os perfis dos autores das obras originais e das traduções. Enquanto a média de idade dos autores traduzidos é de 52 anos, sendo Hermann Weyl o mais novo deles, na época com 37 anos, a média de idade entre os autores originais é de 40 anos. Na verdade, dos 21 autores que a Biblioteca Nacional da França indica a idade, dez não passavam dos 36 anos quando publicaram suas primeiras obras na casa editorial. Gustave Juvet tinha 26 anos quando publicou seu primeiro livro na Blanchard, e Theodoro Ramos tinha 37 anos. 
Collection de Monographies scientitiques étrangères publiées sous la direction de M. G. Juvet, Professeur a I. Université de Lausanne,

I. WEYL (H.). Temps, Espace, Matièré. - Leçons sur la théorie de la relalivité générale, trad. par G. Juvet et R. Leroy. $\mathrm{x} 922, \mathrm{I}$ vol. in $-80 \mathrm{bl}$., $290 \mathrm{p}$. et $\times 5 \mathrm{fig}$. $25 \mathrm{fr}$.

II. BORN'(M.); La Constitution de la Matière. 1922, s vol. gr. in.80 br., 84 p., 36 fig. . . . . . . 7 fr.

UI. KOSSEL (W.). Les Forces de valence et les Spectros de Röntgen. Deux mémoirés sur la structure électronique de l'atome. 1922, $x$ vinl., gr. in $-8^{\circ} \mathrm{br} ., 70 \mathrm{p}$, , rrifig. $7 \mathrm{fr}$.

IV. SOMMEREELD (A.). La Constitution de l'atome et les Raies spectrales, traduit par H. Bellenot. 192/4, 2 fasc. gr. in $-80 \mathrm{br} .7 / 33 \mathrm{p}$, et $\mathrm{x}_{2} 3 \mathrm{fig}$. . . . . $70 \mathrm{fr}$.

V. RIGGI et LEVI-GIVIXA. Máthode de calcul différentiel absolu et leurs applications. ${ }^{9} 9_{23} 3$, broch. gr. in $-8^{\circ}$, 77 pages. . . . . . . . . . $15 \mathrm{fr}$.

VI. W'EGENER (A.). La Genèse des Continents et des Océans, trad. par $M$ : Reichel, $x^{2} g^{2} /$, $x$ yol, gr. in $-8^{\circ} \mathrm{br}$., x6r p., 44 fig. ........... $18 \mathrm{fr}:$

VH. JEANS (J.-H.). La Theorie dynamique des Gaz, trad. par A. Glerc; rg2t, ir vol. gr. in $-8^{\circ}$ br., 5 co p. 25 fig. . . . . . . . $60 \mathrm{fr}$.

VHI. JEANS (J.-H'). Thêorie dú rayonnement et des Quanta, trad. G. Juvèt. r925, r vol. gr. in $8^{\circ} \mathrm{br}$, r23 p. $15 \mathrm{fr}$.

IX. LEBEDEF (Q.). Pression de Ia, Iumière, trad. par Kous-

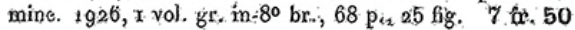

X. THOMSON (Sit J-J.), L'Electron en shimie, avec pré-

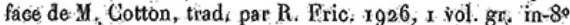
hr.. $\times 35$ p. et $4 \times \mathrm{fig}$. . . . . 20 fr.

XI. LASAREFE (Prof Dr.). Theorie ionique de l'excitatión des tissus vivants, t(g) 8 , $x$ vol. gr. in +80 br. . . . . . . $40 \mathrm{fr}$.

XII. THOMSON (Sir J

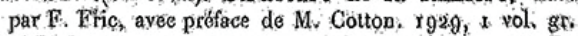
in $88^{\circ} \mathrm{br}_{\mathrm{i}}, \ldots, \ldots, \ldots, 10 \mathrm{ft}$

XIE. BIRfWTSTLE. La nouvello mécaniquo des Quanta, traduction aumentec de / appendices, par MMi Ronte et Rocard. Preface do MiJ. Hadamard, igpa x yol in -80 br. . , , $75 \mathrm{fr}$.

Figura 1: Catálogo da Coleção de Monografias Científicas Estrangeiras, coordenado por Gustave Juvet (Pacotte, 1929)

Além disso, os autores traduzidos foram bastante citados no Jahrbuch über die Fortschritte der Mathematik (https://www.emis.de/projects/JFM/JFM.html), famoso anuário das ciências matemáticas editado na Alemanha no período, enquanto a maioria dos jovens autores não possuía nenhuma citação na época da edição de seus livros na Blanchard. ${ }^{5}$

No que se refere à visibilidade no mercado editorial francês, fenômeno um pouco diferente acontece. Quatorze autores (31\%) dos que publicaram originais pela Blanchard tinham ao menos uma obra editada por alguma editora francesa na época, enquanto 19 não possuíam livros editados na França nem resenhados no Jahrbuch, caso de Theodoro Ramos. Ao passo que, entre os autores da Coleção de Monografias Científicas Estrangeiras, editada por Juvet, somente Joseph John Thomson e Max Planck tinham obras editadas em francês. Planck publicou, em 1913, suas Lições de termodinâmica pela Hermann et Fils, e Thomson, dois livros sobre eletricidade e gás, em 1900 e 1912, e um terceiro sobre teoria atômica, em 1919, todos pela editora Gauthiers-Villars.

Ou seja, de maneira geral, quando editava obras originais, Albert Blanchard apostava em jovens, desconhecidos, tendo alguns deles alguma inserção no mercado interno francês. 
Ao passo que, quando publicava traduções, investia em figuras bastante importantes na comunidade científica internacional, mas que não possuíam até então grande entrada nas prateleiras das livrarias francesas.

Nessa primeira fase, de 1922 a 1932, o catálogo da editora apresenta obras de geologia, história das ciências, medicina e matemática, mas a física moderna e a teoria da relatividade são seus temas principais, sendo a Coleção de Monografias Científicas Estrangeiras seu carro-chefe.

A escolha do editor é bem pensada porque, até então, a teoria da relatividade na França não tinha alcançado um público mais amplo, além dos especialistas. Segundo Michel Paty (1987, p.113), "com raras exceções, o ensino, os livros textos, e os programas das disciplinas universitárias refletem a indiferença em relação ao tema até os anos 1950. A hostilidade foi evidente entre as posições acadêmicas mais importantes até meados dos anos 1920".

O ano em que Blanchard inicia sua casa editorial, 1922, é paradigmático para a teoria da relatividade na França. É quando Albert Einstein visita pela primeira vez Paris a convite de Paul Langevin, a primeira visita de um cientista alemão famoso à França após o término da Primeira Guerra Mundial. Segundo Michel Biezunski (1981), leitor das correspondências entre Langevin e Einstein, o objetivo principal da visita seria elucidar uma série de dúvidas que os especialistas franceses tinham em relação à teoria da relatividade. Contudo, a visita acabou sendo o estopim para uma série de debates nos jornais, alcançando uma audiência bem maior do que a dos especialistas.

Não havia melhor momento para um jovem editor de obras científicas tentar lançar no mercado francês as traduções de obras da área que até então não tinham alcançado grande atenção de um público mais amplo. Para Gustave Juvet, jovem aluno estrangeiro que participava dos seminários de Langevin e Hadamard no Collège de France, era a situação ideal para associar seu nome a importantes especialistas da física moderna e da teoria da relatividade. A perspicácia econômica de Blanchard o leva a publicar até textos críticos à teoria da relatividade, como os livretos de Christian Cornélissen, As alucinações dos einsteinianos ou os erros de método dos físicos matemáticos, de 1926, e de Henri Bouasse, Uma questão prévia contra a teoria de Einstein, de 1923.

Teríamos então uma chave para compreender as razões da edição do livro de cálculo vetorial de Theodoro Ramos na França. O cálculo vetorial era uma disciplina de entrada para se compreender a física moderna, sobretudo a teoria da relatividade, e Ramos era mais uma das novas apostas da Blanchard.

Seu catálogo de obras editadas nos leva a considerá-lo um passeur culturel, "aquele que está em contato com duas culturas oriundas seja de estratos sociais diferentes seja de outros lugares geográficos" (Cooper-Richet, 2005, p.13), que coloca em conexão mundos que possuem dificuldades de ser conectados. Ao editar traduções de livros da Alemanha, da Inglaterra e da Rússia, de temas que começam a desfrutar de certa visibilidade entre o público geral francês, logo após a Primeira Guerra Mundial, ele passa a se tornar um importante nó de uma rede de circulação de impressos científicos, conectando a Rússia e a Alemanha à França e, por conseguinte, ao Brasil. A edição do livro de Ramos nos leva a considerar essa circulação como um fenômeno de mão dupla, ou seja, também do Brasil para a Europa. 
Aquilo que, em um primeiro momento, parece ser um fenômeno localizado, francês ou brasileiro, demanda agora uma "história em perspectiva transnacional" (Saunier, 2013, p.4), que segue o fluxo internacional de cientistas, instrumentos científicos e outros materiais (Turchetti, Herran, Boudia, 2012, p.327). Isso nos ajuda também a reavaliar a matemática moderna como fruto de uma colaboração entre várias partes do mundo, e não como um fenômeno localizado, europeu. Kapil Raj (2015) tem insistido em uma modernidade produzida por vários centros do mundo e que as negociações culturais envolvidas na circulação dos objetos são uma das melhores estratégias para se compreender a produção de conhecimento global e das ciências modernas.

Ademais, nesse trânsito global, é preciso levar em conta uma não estabilidade do texto científico, as suas modificações e apropriações quando transitam de um lugar geográfico a outro ou pelas várias camadas da cadeia de produção editorial (Chartier, 2002; Chartier, Ginsburg, 24 dez. 2016). Assim, não estamos abraçando uma perspectiva difusionista da matemática ou da física moderna, mas tentando elucidar os elementos que colocam em trânsito uma determinada teoria ou objeto e em que medida esse deslocamento os modifica.

\section{Da perspectiva de Paris...}

Embora as contribuições de Newton e Leibniz ao cálculo, na virada do século XVII ao XVIII, os tenham colocado como personagens fundamentais da disciplina, o uso do cálculo nos problemas físicos se deu de maneira sistemática somente ao longo do século seguinte, sobretudo pelas mãos de franceses como Jean D'Alembert e Joseph-Louis Lagrange, pela família de suíços Bernoulli e seus alunos, como Leonhard Euler (Hankins, 2002). Ao colocarem o cálculo como ferramenta central em seus trabalhos, a arte de derivar e integrar tornou-se um saber incontornável para aqueles que quisessem estudar as ciências matemáticas.

Assim é que, ao longo do século XIX, não se conhece escola de engenharia que não tivesse em seus primeiros anos o cálculo como disciplina obrigatória. Além disso, quando olhamos os currículos, livros e ementas de cálculo no período somos levados a concluir que a estrutura principal da disciplina sofreu poucas modificações.

Comparando, por exemplo, a segunda edição dos dois volumes do Traité du calcul différentiel et du calcul intégral, de Sylvestre Lacroix, que serviram de base para as traduções dos primeiros livros de cálculo de várias escolas de engenharia não francesas e também para a Academia Real Militar de dom João VI, fundada em 1812 (Siqueira, Mormêllo, 2011), e os Premiers éléments du calcul infinitesimal, de Sonnet, de 1869 e 1902, usados na Escola Politécnica de São Paulo (Oliveira, 2004), no início do século XX, vemos que os principais tópicos da disciplina se mantiveram. Estudavam-se essencialmente as técnicas de diferenciação para funções de uma ou mais variáveis, depois algumas aplicações, sobretudo na representação de funções em séries e na teoria das curvas planas. Em um segundo bloco, as técnicas de integração, suas aplicações ao problema da quadratura e dos volumes, e, por fim, as equações diferenciais, onde se podia ver uma série de aplicações a problemas físicos.

Ao mesmo tempo que se verifica essa estabilidade na disciplina, a interação entre as teorias da eletricidade, do magnetismo e do cálculo diferencial e integral, desde meados 
do século XIX, criou uma série de conceitos e resultados matemáticos e físicos que, após ganharem um tratamento vetorial, deram origem ao cálculo vetorial (Katz, 1979; Crowe, 2011). Os primeiros livros coligindo os principais resultados dessa nova área começaram a ser editados a partir da década de 1880, nos EUA (The elements of vector analysis, de J. Willard Gibbs, de 1881; e Vector analysis, de J. Willard Gibbs e Edwin Bidwell Wilson, de 1901), na Inglaterra ("The elements of vectorial algebra and analysis", como capítulo da Electromagnetic theory de Heaviside, de 1893), na França (Le calcul vectoriel et sés applications en géométrie et en mécanique, de Nédélec, de 1897), na Alemanha (Einführung in die Vektoranalysis mit Anwendungen auf die mathematische Physik, de R. Gans, de 1905), e na Itália (Elementi di calcolo vettoriale, de Burali-Forti e Marcolongo, de 1909). São indicativos, portanto, de que o cálculo vetorial começa a ser incorporado aos currículos universitários na virada do século XIX para o XX.

A temática também começa a ser captada pelas bibliografias da área de matemática e ciências correlatas, embora a nomenclatura dependesse do lugar e do período: ora era análise, ora era cálculo. A oscilação é característica de uma área em formação. A expressão análise vetorial (Vektoranalysis) só vai aparecer explicitamente no JFM, em 1905, no verbete "Equações, álgebra universal e análise vetorial", como subárea da álgebra. Em 1916, ela deixa a álgebra e passa a ser uma subárea independente na geometria, sendo substituída, em 1924, pela expressão "cálculo tensorial e vetorial" (Vektor und Tensorrechnung). Antes de 1905, os trabalhos que tinham no título alguma dessas expressões acabavam por ser classificados como geometria analítica ou álgebra, em muitos casos ligados a problemas de coordenadas.

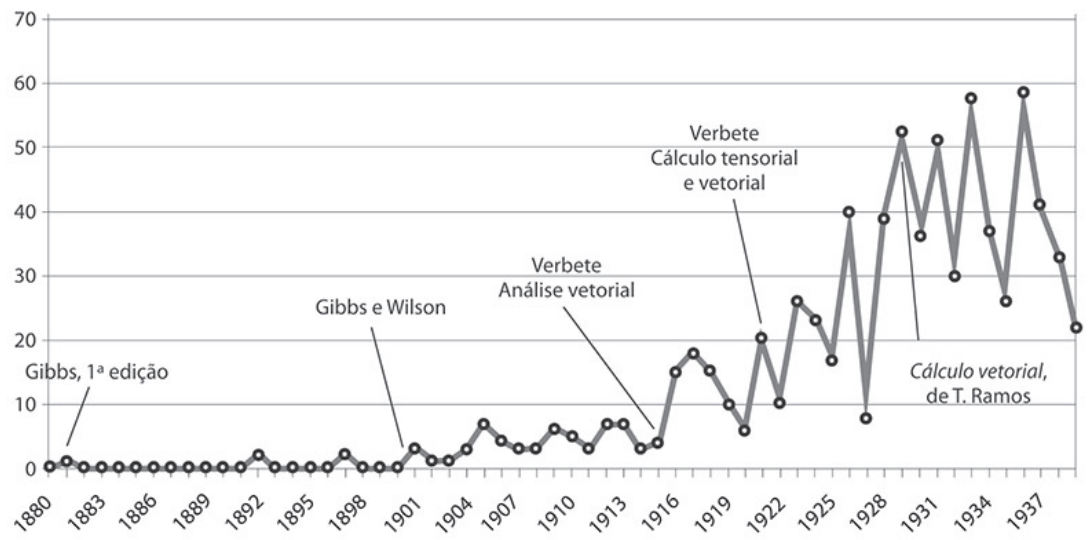

Figura 2: Número de resenhas sobre cálculo vetorial no JFM, de 1880 a 1939 (https://www.emis.de/projects/JFM/JFM.html)

Conforme avançamos nas primeiras décadas do século XX, o número de resenhas aumenta (Figura 2) e uma inflexão importante ocorre: o cálculo tensorial é agregado ao cálculo vetorial. Enquanto o cálculo vetorial está muito ligado à geometria das curvas e superfícies e às aplicações às teorias eletromagnéticas, a teoria de tensores vai ser muito útil nos cálculos da teoria da relatividade. Vale lembrar, no entanto, que, a despeito dessas aplicações, há uma vertente dentro da área que se ocupa exclusivamente de questões internas 
à teoria sem qualquer aplicação ou conexão com a engenharia, ou seja, uma abordagem típica da matemática moderna. Como veremos, o livro de Theodoro Ramos tentará conciliar essas tensões em um mesmo texto.

Em todo o período, o anuário JFM capta majoritariamente trabalhos em inglês (29,3\%), alemão $(22,1 \%)$, francês $(17,8 \%)$ e italiano $(18,8 \%)$. O restante das resenhas (12\%) é de trabalhos em uma infinidade de línguas em que o português é ainda um idioma muito pouco coberto. Ramos, ao publicar em francês, consegue contornar esse problema de visibilidade e acaba por ter o seu trabalho resenhado. Em 1933, o próprio editor do JFM, Georg Feigl (1890-1945), apresenta os seguintes comentários sobre o livro:

Este livro surgiu a partir dos cursos que o autor proferiu, como responsável da cátedra de Teoria dos Vetores da Politécnica de São Paulo, para os engenheiros estudantes de física teórica. Na seção introdutória são desenvolvidos os elementos da álgebra vetorial. $\mathrm{O}$ autor faz uso das seguintes notações, comuns em países de língua latina: Vetores: letras latinas em negrito. Produto interno de $\mathrm{u}$ e $\mathrm{v}: \mathrm{u} \times \mathrm{v}$, Produto externo de $\mathrm{u}$ e v : u $\wedge$ v. No capítulo I, o autor trata dos campos escalar e vetorial, por um lado os colocando em relação com o conceito de gradiente, por outro lado, com as aplicações rudimentares da geometria diferencial métrica das curvas espaciais e superfícies. No capítulo II, adentra ainda mais a análise vetorial: divergentes, rotacionais, o teorema das integrais de Stokes e algumas aplicações à física teórica. No capítulo III, discute os elementos do cálculo tensorial (álgebra tensorial e diferenciação covariante) com uma aplicação sobre a mecânica do contínuo (Feigl, 1933, p.658-659).

A resenha de Feigl é sóbria, discricionária, se comparada com a defesa que René Garnier faz do livro de Theodoro Ramos. Ela acaba sendo repetitiva porque o editor termina depois da descrição dos capítulos reproduzindo detalhadamente o índice do livro de Ramos. É particularmente interessante compará-la com outra resenha que o livro obteve, no número 50 da Rivista Scientia, em 1931. Nesta última, de caráter francamente positivo, Palatini faz elogios às notações adotadas por Ramos, similares à da escola italiana:

O livro do Sr. Ramos se distingue dos outros por sua sobriedade e clareza de exposição, pelos critérios com os quais são introduzidos os diversos conceitos e pela boa generosidade das notações adotadas (elas são substancialmente aquelas da escola italiana, e ele provou doravante que elas são as mais práticas e as mais úteis). Observo somente que, para obter certos resultados, não me parece oportuno recorrer, como fez o autor, às notações conhecidas da mecânica: por um lado, a teoria dos vetores deve fornecer um capítulo de geometria pura; de outro, é justamente a mecânica que é a primeira ciência da aplicação em que se pode demonstrar toda a eficácia do método vetorial, recorrendo aos resultados obtidos na teoria geométrica.

O autor continua a exposição dos métodos apresentando algumas aplicações relativas ao estudo das curvas e superfícies e de certos teoremas do cálculo integral. O volume contém enfim uma introdução ao cálculo tensorial (em que o autor se restringe, no entanto, às variedades de três dimensões), e ainda uma aplicação às equações do equilíbrio em um meio continuamente deformável (Palatini, 1931, p.392-393).

Está em jogo, em primeiro lugar, para os resenhistas, as notações utilizadas por Theodoro Ramos em seu livro. Enquanto Gibbs e a escola americana usavam "a.b" para denotar o produto escalar dos vetores a e b, a escola italiana de Burali-Forti e 
Marcolongo usava " $\mathrm{a} \times \mathrm{b}$ ". Ao passo que, para o produto vetorial, os americanos usavam " $\mathrm{a} \times \mathrm{b}$ ", enquanto os italianos, "a^b". Operações diversas sendo representadas por um mesmo símbolo. Nas primeiras décadas do século XX, a confusão sobre questões desse tipo era tamanha que, no Congresso Internacional de Matemáticos (ICM) de Roma, em 1907, algumas medidas foram discutidas para resolver o problema, mas, segundo BuraliForti e Marcolongo, elas se revelaram infrutíferas. No ICM de Cambridge, em 1912, um plano foi colocado em curso de modo que propostas fossem votadas no ICM de 1920, mas a guerra interrompeu as negociações, e a questão permaneceu indefinida. Feigl fala de uma tradição dos "países de língua latina", embora Burali-Forti e Marcolongo (1914, p.174) digam explicitamente que suas notações respeitam "os trabalhos fundamentais de Möbius, Hamilton, Grassmann e Peano". O aluno de Biggs, Edwin Wilson, defenderá a tradição americana (Wilson et al., 1911; Wilson, 1913). Theodoro Ramos está atento aos debates e escolhe a notação italiana. Outros autores preferem apresentar uma tabela cotejando as notações, como fez Raoul Bricard em seu Le calcul vectoriel de 1929, editado pela Librairie Armand Colin.

Outro elemento que aparece nas resenhas diz respeito ao tratamento que Ramos dá à teoria de vetores no início de seu livro. Em seus primeiros parágrafos, o engenheiro brasileiro introduz o conceito de vetor como "a velocidade de translação de um sólido", "a força aplicada a um corpo em equilíbrio", "a força em ponto de um campo newtoniano" (Ramos, 1930, p.1). São tentativas de aproximar a temática aos engenheiros e às aplicações, o que para Palatini (1931, p.392) parece ser uma estratégia "pouco oportuna". O tratamento da teoria vetorial deveria ser feito, segundo o resenhista italiano, como geometria pura, o que, na época, queria dizer simplesmente um tratamento axiomático, preocupado com os fundamentos da disciplina. Além disso, a teoria dos tensores, uma extensão do cálculo vetorial criada para dar conta de geometrias em dimensões superiores, é apresentada por Ramos em um formato mais simplificado, em três dimensões, o que causa estranheza a Palatini. Enquanto no Brasil o livro significou um passo em direção à separação das matemáticas da engenharia, na Europa ele é visto como uma concessão às aplicações.

\section{Aspectos materiais de um livro de cálculo vetorial: folhas, mise-en-page, figuras e preços}

Em um já clássico sobre a história dos livros de matemática, Gert Schubring (2003, p.126) sugere três dimensões do livro a ser perseguidas quando de um estudo de um livro-texto: as mudanças nas suas várias edições; as mudanças similares em outros livros-texto do mesmo tema; e as mudanças curriculares, epistemológicas e de contexto imbricadas naquele conjunto de textos. Quando seguimos o Cálculo vetorial de Theodoro Ramos em seus trânsitos transnacionais, entre o Brasil e a Europa, mais algumas variáveis envolvidas na edição e circulação de um texto como esse puderam ser identificadas. É preciso incorporar a essas dimensões as várias restrições econômicas envolvidas na produção do texto científico que modificam seu resultado final e que, às vezes, explicam o aparecimento daquele texto em uma determinada editora. É preciso incorporar, portanto, os aspectos materiais envolvidos na produção do livro que modificam seu texto. 
Por volta de 1930, época da publicação do tratado de Theodoro Ramos, havia no mercado francês outros tantos livros sobre cálculo vetorial, que aparentemente concorriam com a obra recém-lançada pela Albert Blanchard. De 1897 a 1932, foram publicados na França 12 livros, incluindo na contagem uma reedição (Quadro 1).

Quadro 1: Livros de cálculo vetorial publicados na França de 1897 a 1932

\begin{tabular}{|c|c|c|c|c|}
\hline Autor & Título & Editora & Ano & Páginas \\
\hline Bricard & Le calcul vectoriel. 2. ed. & Armand Colin & 1932 & 199 \\
\hline Nillus & Leçons de calcul vectoriel & Eyrolles & 1931 & 347 \\
\hline Ramos & Leçons sur le calcul vectoriel & Blanchard & 1930 & 119 \\
\hline Bricard & Le calcul vectoriel & Armand Colin & 1929 & 199 \\
\hline Mallet & $\begin{array}{l}\text { Exposé élémentaire du calcul vectoriel et de quelques } \\
\text { applications }\end{array}$ & Gauthier-Villars & 1927 & 69 \\
\hline Egnell & $\begin{array}{l}\text { L'ochématique (le calcul vectoriel): ses applications } \\
\text { géométriques et ses rapports avec le calcul différentiel } \\
\text { absolu }\end{array}$ & Gauthier-Villars & 1926 & 572 \\
\hline $\begin{array}{l}\text { Chatelet; Kampé } \\
\text { de Fériet }\end{array}$ & $\begin{array}{l}\text { Calcul vectoriel: théorie applications géométriques } \\
\text { et cinématiques destiné aux élèves des classes de } \\
\text { mathématiques et physiques }\end{array}$ & Gauthier-Villars & 1923 & 425 \\
\hline Pomey & Principes de calcul vectoriel et tensoriel & Chiron & 1923 & 319 \\
\hline $\begin{array}{l}\text { Coffin; Véronnet; } \\
\text { Appell }\end{array}$ & $\begin{array}{l}\text { Calcul vectoriel: avec applications aux mathématiques } \\
\text { et à la physique }\end{array}$ & Gauthier-Villars & 1914 & 212 \\
\hline Guiot & Le calcul vectoriel et ses applications à la géométrie réglée & Hermann et fils & 1912 & 128 \\
\hline $\begin{array}{l}\text { Burali-Forti, } \\
\text { Marcolongo; } \\
\text { Lattès }\end{array}$ & $\begin{array}{l}\text { Éléments de calcul vectoriel avec de nombreuses } \\
\text { applications à la géométrie: à la mécanique et à la } \\
\text { physique mathématique }\end{array}$ & Harmann et Fils & 1910 & 229 \\
\hline Nédélec & $\begin{array}{l}\text { Le calcul vectoriel et ses applications en géométrie et en } \\
\text { mécanique }\end{array}$ & $\begin{array}{l}\text { Gauthier-Villars } \\
\text { et Fils }\end{array}$ & 1897 & 246 \\
\hline
\end{tabular}

Fontes: <https://catalogue.bnf.fr/index.do > e <https://www.emis.de/projects/JFM/JFM.html>.

Em sua maioria, eram livros com número de páginas bastante superior ao de Ramos, o que em princípio seria uma vantagem para a construção do preço da obra da Blanchard. Menos material, menos papel, menor o preço. No entanto, o número de páginas não era o único fator que contava no preço de uma obra. O tamanho e o tipo das páginas, a presença de gravuras e o espaçamento das letras e parágrafos eram elementos importantes.

De fato, o preço de capa do Cálculo vetorial de Theodoro Ramos era de 25 francos, tendo 119 páginas, formato in-oitavo (em torno de $20 \times 13,5 \mathrm{~cm}$ ), sem nenhuma figura. ${ }^{6}$ No mesmo período, a Armand Collin oferecia um livro de 199 páginas, por nove francos. ${ }^{7}$ A explicação da diferença estava no formato do livro da Collin, no tipo das páginas e em seu conteúdo: seu formato era in-dezesseis, conteúdo bem enxuto, quase como um resumo rápido, e as folhas eram de um papel mais escuro, de qualidade inferior. Tais formatos e variações de conteúdo parecem desempenhar papéis distintos no mercado livreiro. Assim, uma mesma casa editorial acaba publicando livros com conteúdo similar, mas com propostas distintas, de modo a cobrir a diversidade do mercado consumidor. Isso explicaria a quantidade de livros sobre cálculo vetorial sendo editada por uma mesma casa editorial, a Gauthiers-Villars. 
Dentro de uma mesma editora, as variações do tipo e da quantidade de papel constituem às vezes uma maneira de manter um catálogo com preços pouco discrepantes. No mesmo catálogo, em que o Cálculo vetorial de Ramos aparece, o livro Os fundamentos da matemática, de Gonseth, editado em 1926, era oferecido também por 25 francos. O editor omite o número de páginas no catálogo, mas o leitor irá perceber que a qualidade do papel é bem inferior, mais escuro do que a da obra de Ramos, embora o número de páginas fosse 243 e o livro viesse repleto de gravuras, ou seja, com soluções gráficas que justificavam o preço. As soluções conceituais devem ser a todo tempo equilibradas com as soluções gráficas e, portanto, com os custos de edição de uma obra.

\section{Da perspectiva de São Paulo}

Quando comparamos a obra em francês de Ramos e sua edição original em português, essas diferentes soluções gráficas ficam mais evidentes. A primeira versão do livro havia sido publicada em 1927, como notas de aula, pela Tipografia Brazil de Rothschild \& Co. (Ramos, 1927). Baseadas em um curso esporádico que Ramos ministrava, anos antes, na Escola Politécnica, e transcritas pelos alunos Ayr Albuquerque e Pedro A. Fleury da Silveira, as notas são divididas em duas partes. Na primeira, de aproximadamente 54 páginas, o autor faz um apanhado da teoria de vetores, suas propriedades, operações (soma, produtos escalar, vetorial e misto), e aplicações geométricas, como o cálculo de ângulos e distâncias, e a apresentação das equações vetoriais para retas e planos. Já na segunda parte, de aproximadamente 126 páginas, Theodoro Ramos apresenta as funções vetoriais, sua derivação e integração, os conceitos de rotacional e divergente, as aplicações geométricas da teoria (o cálculo das tangentes, normais, curvaturas tanto de curvas quanto de superfícies), e os teoremas do gradiente, de Stokes, da divergência e de Green, largamente usados na teoria da eletricidade e magnetismo. Na época, era um curso de cálculo voltado para estudantes de engenharia interessados em física teórica, conforme diz o prefácio da versão francesa.

No mesmo ano, Christovam Colombo dos Santos, professor da Escola de Minas de Ouro Preto, publicou um conjunto de lições chamadas também de "Cálculo vetorial". Tudo indica que os engenheiros trabalharam de maneira independente, porque Santos (1927, p.3) diz, no prefácio do seu livro, que "para a difusão do método vetorial, é a primeira contribuição, escrita em nossa língua, a não ser o resumo das operações fundamentais que o professor Gastão Gomes fez proceder à sua Mecânica". Nomes idênticos, mas propostas com diferenças importantes. Embora as introduções às operações com vetores sejam bastante similares, Santos constrói seu texto até a definição vetorial das equações de superfície, enquanto, como já observamos, Ramos chega a apresentar os teoremas de Green e Stokes, de maneira muito próxima ao que se faz atualmente nas disciplinas de cálculo.

Na versão francesa do livro de Ramos, as 54 páginas sobre vetores foram reduzidas para 24, enquanto a segunda parte de 126 páginas, que terminava com os teoremas de fluxo e divergência, foi dividida em dois capítulos cujo tamanho total passou a ser de 62 páginas. Theodoro Ramos ainda introduziu na versão francesa um terceiro e novo capítulo sobre cálculo tensorial de aproximadamente trinta páginas. Além disso, comparando as características bibliométricas dos livros, percebe-se que o formato de 
ambos era praticamente o mesmo (in-oitavo). Também o tipo de papel e o tamanho das letras eram bastante similares. O que parece divergir entre uma versão e outra é a largura da mancha da versão em francês, que aparenta ser ligeiramente menor que a original em português, ou seja, as páginas na versão francesa passaram a comportar uma quantidade menor de texto.

Portanto, o número menor de páginas, o aumento de conteúdo e a ausência de figuras na versão francesa sugerem que Ramos teve que redesenhar drasticamente seu livro para que ele pudesse ser publicado na França, pela Albert Blanchard, por 25 francos. Ele novamente está atento às mudanças da área, quando introduz uma parte sobre cálculo tensorial, tema que passou a discutir no começo dos anos 1920 (Figura 2). Apesar disso, a solução não parece competitiva economicamente. Seu conteúdo maior e mais detalhado do que o do livro de Bricard (in-dezesseis, 199p., nove francos) da Armand Collin, mas não conseguia fazer frente ao de Coffin (in-oitavo, 212p., 15 francos) com conteúdo similar, da Gauthier-Villars.

Se o livro de Theodoro Ramos não tinha um bom preço, capaz de competir com seus congêneres na França, ele obteve mesmo assim algumas resenhas que lhe garantiram alguma visibilidade na Europa e em São Paulo. Como já foi dito, uma delas foi reproduzida no jornal O Estado de S.Paulo, em agosto de 1931, na mesma época em que Theodoro Ramos foi secretário de Educação e Saúde Pública.

Na Escola Politécnica, não havia referência ao cálculo vetorial até então. Ele só passou a constar explicitamente no regulamento da escola, no decreto de 13 de junho de 1931, como uma das aulas da cadeira de "Geometria analítica e projetiva. Nomografia. Cálculo vetorial". Três anos depois, em 6 de abril de 1935, o regulamento trazia a cadeira "Cálculo vetorial, mecânica racional", pela qual Theodoro Ramos já era conhecido anos antes. Na nova Faculdade de Filosofia, Ciências e Letras (FFCL), da Universidade de São Paulo, para onde Ramos se transferiu como novo diretor, a disciplina se chamava "Mecânica racional precedida de cálculo vetorial".

Nas duas escolas, o conteúdo das disciplinas era igual: tratamento vetorial das curvas, das superfícies e o estudo dos campos vetoriais a partir do cálculo diferencial e integral, terminando com os teoremas de Green e Stokes. O formato era muito próximo da versão em português do livro de Ramos (EPSP, 1932, 1933, 1934, 1936, 1946; FFCL, 1934-1935, 1936, 1937-1938, 1939-1949). Não há em nenhum dos casos a discussão do cálculo tensorial contida na última parte do livro.

$\mathrm{Na}$ opinião dos alunos e colegas engenheiros, as aulas e o livro em francês eram similares, incluída a parte sobre cálculo tensorial. Quando da morte de Theodoro Ramos, em 1936, o engenheiro pernambucano Luiz Freire (5 maio 1936) observou que Ramos havia se voltado "à brilhante escola italiana, sobretudo na parte que se refere à ciência dos vetores e sua natural extensão, os tensores". Já o professor da Escola Politécnica de São Paulo Francisco Emídio da Fonseca Telles, que seguiu as aulas de Ramos sobre o tema, sugere que a disciplina ia "das primeiras noções sobre vetores até a introdução ao cálculo tensorial". Telles (1936, p.94) complementa que Ramos tanto nas aulas quanto no livro apresentava "rigor nas demonstrações" e uma "feliz intercalação de aplicações do cálculo vetorial à mecânica". Aos olhos de outros engenheiros do período, portanto, Theodoro Ramos dispõe de habilidades úteis às duas áreas às quais pertence: nas aplicações tão 
caras à engenharia e no rigor das demonstrações, qualidade que os matemáticos modernos costumavam cultivar.

Embora engenheiros e matemáticos em São Paulo estivessem em franco processo de separação, a disciplina tinha chegado a uma tal estabilidade em fins dos anos 1930 que os conteúdos nas duas escolas eram iguais. Isso se deve também ao fato de que, até o começo dos anos 1940, muitos professores da FFCL ainda lecionavam na Escola Politécnica (Silva, Siqueira, 2017).

O livro e seu autor, bem como suas relações com a Itália, foram também objeto de riso entre os alunos. Como parte das suas tarefas na organização da Universidade de São Paulo, Theodoro Ramos viajou para a Europa a fim de contratar professores para as seções de física e matemática da FFCL. Para as cadeiras de matemática e física, um conjunto de professores chamado Missão Italiana chega ao Brasil como fruto de uma longa negociação que envolveu intelectuais, políticos e membros da elite tanto do Brasil quanto da Itália (Silva, 2015; Silva, Siqueira, 2018).

Quando estava prestes a retornar da Itália, Theodoro Ramos fez o seguinte balanço da sua estada na Itália ao jornal O Estado de S.Paulo:

Na Itália, além de ter sido homenageado pelas autoridades, entre as quais é justo salientar o ministro Piero Parini que se mostrou um grande amigo do Brasil, devo relembrar a entrevista que tive com o chefe do governo italiano, sr. Benito Mussolini, de quem trago as melhores recordações. Não se deve também esquecer a atuação desenvolvida pelo sr. Embaixador da Itália no Brasil em prol do sucesso da minha missão na Itália (Silva, Siqueira, 2014).

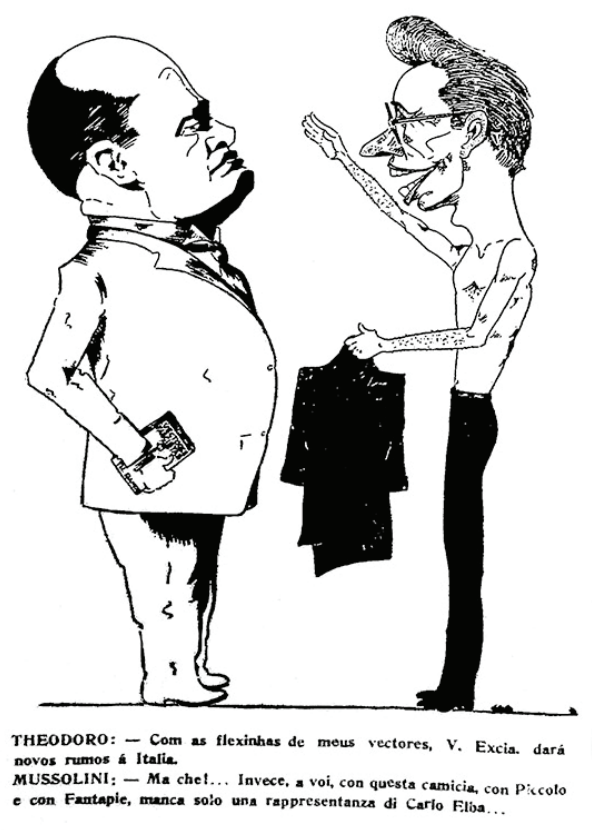

Figura 3: A viagem do Dr. Theodoro; charge em A Minervina, jornal do Centro Acadêmico da Escola Politécnica de São Paulo (A viagem..., 9 jun. 1934) 
Os alunos da Escola Politécnica, dias depois, publicaram em seu jornal A Minervina uma charge de Theodoro em negociação com Mussolini, com o seguinte diálogo:

Theodoro: - Com essas flechinhas de meus vetores, V. Excia. dará novos rumos à Itália.

Mussolini: - Mas o quê!... Já você, com esta camisa, com Piccolo e com Fantapié, fica faltando somente a representação de Carlo Elba... ${ }^{8}$

Além das oposições mais evidentes que a charge indica, "gordo em branco versus magro em preto, ou na ingenuidade de Ramos, risonha, contente, frente a truculência de Mussolini, ou na troca da ciência pela política", quando Ramos oferece seus vetores a Mussolini, há ali uma crítica ao imigrante italiano e às suas práticas culturais. O desconforto com a Missão Italiana dizia respeito muito mais aos problemas de identidade da São Paulo dos anos 1930, do que ao fascismo (Silva, Siqueira, 2014).

Cabe acrescentar a essa interpretação que Carlo Elba era, na verdade, um remédio italiano bastante conhecido em São Paulo, feito de bicarbonato de sódio e indicado para problemas de estômago e gastrite (Bicarbonato..., 15 fev. 1938). A charge ganha então contornos mais claros. Tudo se passa como se, no julgamento dos alunos, enquanto Theodoro Ramos trazia ingenuamente a ciência e a técnica, seus vetores para dar "novos rumos" à Itália, Mussolini lhe retrucava dizendo que, com o uso da indumentária fascista e sua aliança com os dois professores italianos, ele certamente precisaria de um antiácido para os seus futuros problemas estomacais. Em suas mãos, Mussolini traz o livro de Theodoro Ramos agora com um novo nome: "Vetores fascistas". Ramos o saúda com o braço erguido, na diagonal, gesto típico de saudação a Mussolini que será mote de chacota entre os estudantes politécnicos nos meses seguintes (Silva, 2015, p.100).

Assim, a charge se constitui em crítica sutil da elite culturalmente afrancesada, que ao mesmo tempo demonstrava sua repulsa ao italianismo e à ideia de uma ciência que não considerava as interdições culturais interpostas na escolha dos novos professores da Universidade de São Paulo, uma ação pautada puramente por critérios científicos, técnicos, como o próprio Theodoro Ramos se apresenta em seu discurso de posse na Comissão de Saneamento meses antes.

A crítica se constrói em espaço autorizado para o humor, não é direta, textual. No entanto, os ganhos simbólicos de ter um texto publicado em francês são questionados por objeções e desconfianças por ter negociado com Mussolini. O uso dos capitais científicos em questões políticas é lido como uma atitude ingênua do professor politécnico. A galhofa era a resposta dos alunos. Como todo impresso, um livro pode servir de interpretações e apropriações bastante díspares das engendradas pelo seu autor e editor.

\section{AGRADECIMENTOS}

Este trabalho foi financiado pela Fundação de Amparo à Pesquisa do Estado de São Paulo (Auxílios à Pesquisa Fapesp 19/02073-1 e 15/16937-7). O autor agradece aos pareceristas os comentários feitos à primeira versão do trabalho e que enriqueceram a versão final. 


\title{
NOTAS
}

\author{
${ }^{1}$ Nessa e nas demais citações de textos em outros idiomas, a tradução é livre. \\ ${ }^{2}$ Sobre o interventor federal, o engenheiro geógrafo João Alberto Lins de Barros, ver o verbete do Dicionário \\ biográfico do CPDOC (Paula, Lattman-Weltman, 2010).
}

${ }^{3}$ As conotações e rivalidades no período entre os dois partidos e o tenentismo foram descritas em Codato, (2010, p.278).

${ }^{4}$ A Casa de Oswaldo Cruz (COC/Fiocruz) possui em seus acervos o conjunto de cartas de Paulo Carneiro e de membros da sua família. Algumas dessas cartas tratam de negociações estritamente econômicas entre Émile Blanchard e os membros do Apostolado Positivista Paulo Carneiro, S. Vieira Souto e Alípio Bandeira. O principal mote das discussões são as despesas advindas da preservação da Casa de Auguste Comte em Paris e da edição de Wilhelmine, de Clotilde Vaux, pela Blanchard. Ver COC (2018).

${ }^{5}$ Excluindo repetições e contando separadamente as coautorias, o primeiro grupo é composto por 45 autores, e o segundo, por 15. Desses 15 autores, somente três (David D. Leib, Friedrich Wilhelm Hulle e Mario LimaBarbosa) não possuem nenhuma resenha de trabalhos seus no Jahrbuch über die Fortschritte der Mathematik. Ao passo que, entre os autores de obras originais, 33 nunca haviam sido citados no anuário, na época da publicação de seus livros na Blanchard, sendo que 22 destes nunca tinham publicado sequer uma única obra mesmo em francês, ou seja, eram completamente desconhecidos da comunidade de matemáticos e físicos franceses e europeus, conforme apurado na Biblioteca Nacional da França (https://catalogue.bnf. fr/index.do) e no Sistema Universitário de Documentação (http://www.sudoc.abes.fr).

${ }^{6} \mathrm{O}$ livro foi oferecido na contracapa de um livro de história do newtonianismo na França, de Pierre Brunet.

${ }^{7}$ Cf. resenha de Buhl (1929, p.343).

${ }^{8}$ No original: "Mussolini: - Mache! ... Invece, a voi, conquesta camicia, com Piccolo e com Fantappiè, manca solo una rappresentanza di Carlo Elba...".

\section{REFERÊNCIAS}

A VIAGEM...

A viagem do Dr. Theodoro... A Minervina, ano 2, n.5, p.1. 9 jun. 1934.

ALUNNI, Charles.

Gustave Juvet (1896-1936): un pionnier oublié des études cliffordiennes. Advances in Applied Clifford Algebras, v.19, n.3, p.547-584. 2009.

BICARBONATO...

Bicarbonato de Sódio Carlo Elba. Correio Paulistano, p.7. 15 fev. 1938.

BIEZUNSKI, Michel.

La diffusion de la théorie de la relativité en France. Tese (Doutorado em Didática de Ciências Físicas e Tecnologia) - Université Paris VII, Paris. 1981.

BONFIM, Sabrina Helena.

Theodoro Augusto Ramos (1895-1935): uma biografia. Revista Brasileira de História da Matemática, v.14, n.29, p.59-81. 2014.

BONFIM, Sabrina Helena.

Theodoro Augusto Ramos: um estudo comentado de sua tese de doutoramento. Tese (Doutorado em Educação Matemática) - Universidade Estadual Paulista Júlio de Mesquita Filho, Rio Claro. 2013.
BOURDIEU, Pierre.

O campo científico. In: Ortiz, Renato (Org.). A sociologia de Pierre Bourdieu. São Paulo: Olho d'Água. p.112-143. 2003.

BUHL, Adolphe.

Raoul Bricard: Le calcul vectoriel (Collection Armand Colin). L'Enseignement Mathématique, v.28, p.343-344. 1929.

BURALI-FORTI, Cesare; MARCOLONGO, Roberto.

Analyse vectorielle générale: 1 . Transformations linéaires; II. Applications à la mecanique et a la physique (Pavie, Mattei, 1912-1913). Isis, v.2, n.1, p.174-182. 1914.

CÁlCULO VETORIAL...

Cálculo vetorial pelo Prof. Theodoro Ramos. $O$ Estado de S.Paulo, p.2. 1 ago. 1931.

CARAMORI, Leonardo C.

A biblioteca da Escola Politécnica de São Paulo e seus acervos de engenharia civil e arquitetura entre 1894 e 1928. Dissertação (Mestrado em História Social) - Universidade de São Paulo, São Paulo. 2015. 
CHARTIER, Roger.

Textos, impressos, leituras. In: Chartier, Roger. $A$ história cultural: entre práticas e representações. Lisboa: Difel. p.121-139. 2002.

CHARTIER, Roger; GINSBURG, Carlo. Dos hombres y un libro interminable: entrevista de Roger Chartier e Carlo Ginzburg à Fernando Bogado. Página 12. Seção Radar Livros. Disponível em: <https://www.pagina12.com.ar/10496-doshombres-y-un-libro-interminable $>$. Acesso em: fev. 2018. 24 dez. 2016.

COC.

Casa do Oswaldo Cruz/Fundação Oswaldo Cruz. Departamento de Arquivo e Documentação. Acervo Paulo Carneiro. BR RJCOC PC-VP. 2018.

CODATO, Adriano N.

A elite destituída: a classe política paulista nos anos 30. In: Odalia, Nilo; Caldeira, João Ricardo de C.C. (Org.). História do estado de São Paulo: a formação da unidade paulista. v.2: República. São Paulo: Editora Unesp; Arquivo Público do Estado; Imprensa Oficial. p.275-305. 2010.

COOPER-RICHET, Diana.

Introduction. In: Cooper-Richet, Diana; Mollier, Jean-Yves; Silem, Ahmed (Org.). Passeurs culturels dans le monde des médias et de l'édition en Europe (XIXe et XXe siècles). Villeurbanne: ENSSIB. p.13-17. 2005.

CROWE, Michael.

A history of vector analysis: the evolution of the idea of a vectorial system. New York: Dover. 2011.

EHRHARDT, Caroline.

Du cours magistral à l'entreprise éditoriale.

Histoire de l'Education, n.2, p.111-139. 2011.

EPSP.

Escola Politécnica de São Paulo. Anuário da Escola Politécnica de São Paulo. São Paulo: EPSP. 1946.

EPSP.

Escola Politécnica de São Paulo. Anuário da Escola Politécnica de São Paulo. São Paulo: EPSP. 1936.

EPSP.

Escola Politécnica de São Paulo. Anuário da Escola Politécnica de São Paulo. São Paulo: EPSP. 1934.

EPSP.

Escola Politécnica de São Paulo. Anuário da Escola Politécnica de São Paulo. São Paulo: EPSP. 1933.

EPSP.

Escola Politécnica de São Paulo. Anuário da Escola Politécnica de São Paulo. São Paulo: EPSP. 1932.

FARIA, Rodrigo Santos de.

A engenharia entre a técnica e a política na construção dos (disputa pelos) setores públicos de obras urbanas do estado de São Paulo: o caso da Comissão de Obras Novas do Abastecimento de Águas da Capital, 1926-1927. Politeia: História e Sociedade, v.9, n.1, p.173-195. 2009.

FEIGL, George (Org.).

T.A. Ramos: leçons sur le calcul vectoriel. Jahrbuch über die Fortschritte der Mathematik, v.56, n.1, p.658-659. Disponível em: <https://www. emis.de/projects/JFM/JFM.html>. Acesso em: 23 fev. 2018. 1933.

FFCL.

Faculdade de Filosofia, Ciências e Letras da USP. Anuário da Faculdade de Filosofia, Ciências e Letras da USP. São Paulo: FFCL. 1939-1949.

FFCL.

Faculdade de Filosofia, Ciências e Letras da USP. Anuário da Faculdade de Filosofia, Ciências e Letras da USP. São Paulo: FFCL. 1937-1938.

FFCL.

Faculdade de Filosofia, Ciências e Letras da USP. Anuário da Faculdade de Filosofia, Ciências e Letras da USP. São Paulo: FFCL. 1936.

FFCL.

Faculdade de Filosofia, Ciências e Letras da USP. Anuário da Faculdade de Filosofia, Ciências e Letras da USP. São Paulo: FFCL. 1934-1935.

FOI NOMEADO...

Foi nomeado secretário da Educação e Saúde Pública o Dr. Theodoro Ramos. Folha da Manhã, p.1-3. 6 maio 1931.

FREIRE, Luiz.

A obra matemática de Theodoro Ramos. Jornal do Commercio, p.8. 5 maio 1936.

GARNIER, René.

Leçons sur le calcul vectoriel, par T.A. Ramos. $L a$ Quinzaine Critique des Livres et ses Revues, n.25, p.299. 10 jan. 1931.

HANKINS, Thomas.

A matemática e as ciências exatas. In: Hankins, Thomas. Ciência e Iluminismo. Porto: Porto Editora. p.17-45. 2002.

KATZ, Victor J.

The history of Stokes' theorem. Mathematics Magazine, v.52, n.3, p.146-156. 1979.

MOLLIER, Jean-Yves.

$O$ dinheiro e as letras: história do capitalismo editorial. São Paulo: Edusp. 2010.

MOTOYAMA, Shozo.

USP 70 anos: imagem de uma história vivida. São Paulo: Edusp. 2006.

OLIVEIRA, Antonio Sylvio Vieira de. O ensino do cálculo diferencial e integral na Escola Politécnica de São Paulo, no ano de 1904: uma análise documental. Dissertação (Mestrado em 
Educação Matemática) - Universidade Estadual Paulista, São Paulo. 2004.

PACOTTE, Julien.

Les méthodes nouvelles en analyse quantique: mécanique quantique; mécanique ondulatoire. Paris: Albert Blanchard. 1929.

PALATINI, Attilio.

T.A. Ramos: leçons sur le calcul vectoriel; C.E. Weatherburn: differential geometry of three dimensions. Scientia, v.50, p.392-393. Disponível em: <http://amshistorica.unibo.it/7>. Acesso em: 3 mar. 2018. 1931.

PATY, Michel.

The scientific reception of Relativity in France. In: Glick, Thomas F. (Org.). The comparative reception of Relativity. Dordrecht: D. Reidel. p.113-167. 1987.

PAULA, Christiane J. de; LATTMAN-WELTMAN, Fernando (Org.).

José Lins de Alberto Barros. Dicionário biográfico brasileiro da Fundação Getulio Vargas. Rio de Janeiro: Editora da FGV. Disponível em: <http:// www.fgv.br/cpdoc/acervo/dicionarios/verbetebiografico/joao-alberto-lins-de-barros-1>. Acesso em: 31 ago. 2017. 2010.

RAJ, Kapil.

Além do pós-colonialismo... e pós-positivismo: circulação e a história global da ciência. Revista Maracanan, n.13, p.164-175. 2015.

RAMOS, Theodoro.

Leçons sur le calcul vectoriel. Paris: Albert Blanchard. 1930.

RAMOS, Theodoro.

Cálculo vetorial: notas de aula de Ayr

Albuquerque e Pedro A. Fleury da Silveira. São

Paulo: Tipografia Rothschild. 1927.

SANTOS, Christovam C.

Cálculo vetorial. Ouro Preto: Escola de Minas. 1927.

SAUNIER, Pierre-Yves.

Transnational history. London: Palgrave

Macmillan. 2013.

SCHUBRING, Gert.

Análise histórica de livros de matemática: notas de aulas. Campinas: Autores Associados. 2003.

SILVA, Circe Mary da.

Politécnicos ou matemáticos? História, Ciências, Saúde-Manguinhos, v.13, n.4, p.891-908. 2006.

SILVA, Clóvis Pereira da.

Theodoro A. Ramos: sua correspondência para Lélio Gama. Revista da SBHC, n.7, p.11-29. 1997.

SILVA, Luciana Vieira Souza da.

A Missão Italiana da Faculdade de Filosofia,

Ciências e Letras da Universidade de São Paulo: ciência, educação e fascismo, 1934-1942.

Dissertação (Mestrado em Estudos Culturais) Universidade de São Paulo, São Paulo. 2015.

SILVA, Luciana Vieira Souza; SIQUEIRA, Rogério Monteiro.

An Italian mission at the University of São Paulo: science and education issues in the diplomatic relationships between Italy and Brazil in the 1930s. Les Mélanges de l'École française de Rome: Italie et Méditerranée modernes et contemporaines (Mefrim), v.130, n.2, p.407-419. 2018.

SILVA, Luciana Vieira Souza; SIQUEIRA, Rogério Monteiro.

Luigi Fantappiè e seus alunos da FFCL: autonomia e profissionalização da matemática em São Paulo. Revista Brasileira de História da Ciência, v.10, n.2, p.222-232. 2017.

SILVA, Luciana Vieira Souza; SIQUEIRA, Rogério Monteiro.

A Missão Italiana da Faculdade de Filosofia Ciências e Letras da USP e o imaginário da imprensa e do paulistano sobre o fascismo antes da Segunda Guerra. Intellectus, v.13, n.2, p.123141. 2014.

SIQUEIRA, Rogério Monteiro.

Pureza e desinteresse como distinção: as matemáticas entre engenheiros politécnicos na virada dos novecentos para o século 20. História Unisinos, v.22, n.4, p.534-546. 2018.

SIQUEIRA, Rogério Monteiro.

A matemática e seus usos controlados: engenheiros matemáticos positivistas do Brasil Imperial ao Republicano. Tese (Livre-docência em História da Ciência) - Universidade de São Paulo, São Paulo. 2017.

SIQUEIRA, Rogério Monteiro; MORMÊLLO, Ben Hur.

A gênese ilustrada da Academia Real Militar e suas onze reformas curriculares (18101874). História da Ciência e Ensino: Construindo Interfaces, v.3, p.17-30. 2011.

STUDART, Nelson; COSTA, Rogério C. T. da; MOREIRA, Ildeu de Castro.

Theodoro Ramos e a física moderna no Brasil. Física na Escola, v.5, n.2, p.34-36. 2004.

TELLES, Francisco Emydgio de Fonseca. Professor Theodoro Ramos. Anuário da Escola Politécnica de Universidade de São Paulo, ano 5, 2a série, p.91-95. 1936.

TURCHETTI, Simone; HERRAN, Néstor; BOUDIA, Soraya.

Introduction: Have we ever been

'transnational'? Towards a history of science across and beyond borders. The British Journal for the History of Science, v.45, n.3, p.319-336. 2012. 
WILSON, Edwin Bidwell.

The unification of vectorial notations. Bulletin of the American Mathematical Society, v.19, n.10, p.524-530. 1913.
WILSON, Edwin Bidwell et al.

C. Burali-Forti et R. Marcolongo: éléments de calcul vectoriel avec de nombreuses applications a la geometrie, a la mecanique et a la physique mathématique. Bulletin of the American

Mathematical Society, v.17, n.5, p.256-257. 1911.

\section{$\rightarrow \rightarrow \rightarrow<<<$}

